\section{EL PERU TIENE UN DESTINO AERONÁUTICO}

\author{
FIDEL CASTRO HERRERA \\ Cadete EOFAP
}

Perú, país de difícil geografía, históricamente ha presentado dificultades para su integración territorial, cultural y social en el plano interno; en el plano externo al ocupar el lado occidental de América del Sur, de una u otra manera lo alejaba de las zonas más desarrolladas del mundo, con el consiguiente aumento de tiempo y de costos de todas las mercaderías extranjeras necesarias para su desarrollo.

La ventaja de poseer tres regiones y de tener casi todos los climas del orbe, se ha convertido en desventajas desde el punto de vista de la integración vial, todos los esfuerzos desarrollados y las grandes inversiones en infraestructura no han resuelto el problema, porque construir carreteras y ferrocarriles en una geografía tan difícil como la nuestra requiere de mayores recursos fuera del alcance de nuestras posibilidades. La Costa, la Sierra y la Montaña, se erigen como grandes obstáculos naturales para unir las diversas regiones y aprovechar sus riquezas, para establecer intercambios y mejorar los niveles de vida.

El desarrollo de la industria de la aviación y la necesidad de trasladar cantidades importantes de productos perecibles a los mercados mundiales, ha permitido construir unidades aéreas con tarifas de fletes más bajas que antes. Este ejemplo desarrollado en el mundo puede servir a los propósitos de los productores peruanos, quienes no encuentran la forma apropiada de hacer llegar sus productos a los mercados indicados en el momento oportuno.

Recientemente, y en el pasado la FAP (Fuerza Aérea del Perú) ha realizado grandes esfuerzos en integrar las diversas regiones con el aporte de sus unidades, que trasladaban de zonas inaccesibles a los pobladores y sus productos, a los mercados y a las ciudades más importantes. Ante la destrucción provocada por el fenómeno de El Niño, hemos sido testigos de las proezas de nuestra Fuerza Aérea y de cómo la comunidad ha recibido con beneplácito esta tarea que durará durante toda la reconstrucción de los desastres de la naturaleza.

Si relacionamos los dos puntos de arriba, comprenderemos el porqué de la afirmación de que el Perú tiene un destino aeronáutico y de cómo en la práctica esta tarea ha sido realizada ya por nosotros. Nuestra querida FAP está integrando a las regiones más apartadas del país con gran eficiencia, pese a la carencia de aeropuertos y al escaso mantenimiento; si estas experiencias fueran bien aprovechadas y los señores empresarios tuvieran una visión como la nuestra, estoy seguro se iniciaría una nueva etapa en el desarrollo del país y un mejor aprovechamiento de todas las riquezas regionales.

Nuestra geografía es una de las más difíciles del mundo, lo que ha dado lugar a la incomunicación de muchas zonas del país. La Cordillera de los Andes, cuna de grandes civilizaciones, que atraviesa de norte a sur el territorio patrio es el gran obstáculo que se enfrenta para aproximar a los modernos mercados la producción de la Sierra y de la Selva, en este aspecto la industria de la aviación presenta alternativas viables para integrar a los diversos productores domésticos, estableciendo los canales de comunicación modernos y expeditivos. 
Es así como se explica que los aspectos del desarrollo de los aviones (versatilidad, tamaño y rapidez) y la configuración geográfica del Perú obligan a un estudio y entrenamiento exigente y especial a los pilotos FAP, y a la necesidad de impregnarles de nacionalismo, valentía y heroísmo personal para cumplir con el rol que nos corresponde en el umbral del nuevo milenio. 